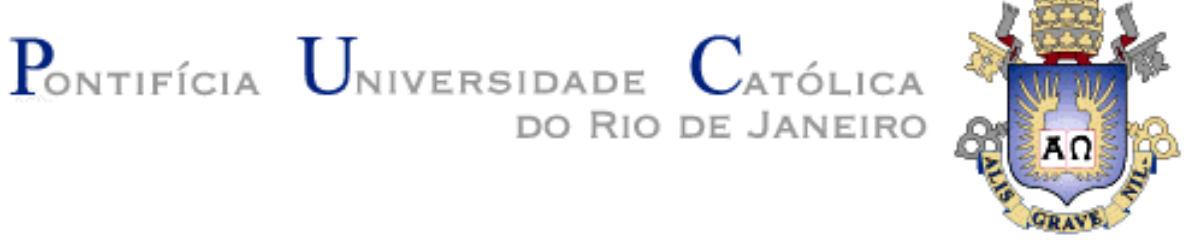

Jucy da Silveira Junior

\begin{abstract}
A Tipologia de Mintzberg Aplicada nos Modelos de Gestão de Serviços B2B no Mercado de Telecomunicações Brasileiro
\end{abstract}

Dissertação de Mestrado

Dissertação apresentada ao Programa de Pósgraduação em Administração de Empresas da PUCRio como requisito parcial para obtenção do titulo de Mestre em Administração de Empresas.

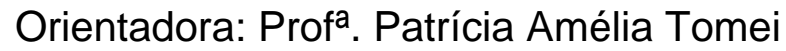

Rio de Janeiro

Setembro de 2010 


\title{
A Tipologia de Mintzberg Aplicada nos Modelos de Gestão de Serviços B2B no Mercado de Telecomunicações Brasileiro
}

\begin{abstract}
Dissertação apresentada como requisito parcial para obtenção do grau de Mestre pelo Programa de Pósgraduação em Administração de Empresas da PUC-Rio. Aprovada pela Comissão Examinadora abaixo assinada.
\end{abstract}

Profa. Patrícia Amélia Tomei

Orientadora

Departamento de Administração - PUC-Rio

Prof. Giuseppe Maria Russo

Departamento de Administração - PUC-Rio

Prof. Mario Couto Soares Pinto

UNESA

Profa. Mônica Herz

Vice-Decana de Pós-Graduação do CCS

Rio de Janeiro, 15 de setembro de 2010 
Todos os direitos reservados. É proibida a reprodução total ou parcial do trabalho sem autorização da universidade, do autor e da orientadora.

\section{Jucy da Silveira Junior}

Engenheiro de Eletricista, com ênfase em Eletrônica e Telecomunicações pelo Instituto Nacional de Telecomunicações (INATEL - 1993). Há 17 anos atuando no mercado de telecomunicações Brasileiro e da América Latina passando por empresas do Grupo Sharp, Lucent e atualmente Alcatel-Lucent. Onde atuou, em vários cargos gerenciais na área de serviços profissionais para operadoras de telefonia, tanto em execução e consultoria como em desenvolvimento de negócios.

Ficha catalográfica

Silveira Junior, Jucy da

A tipologia de Mintzberg aplicada nos modelos de gestão de serviços B2B no mercado de telecomunicações brasileiro / Jucy da Silveira Junior ; orientador: Amélia Tomei. - 2010.

96 f. : il. (color.) ; $30 \mathrm{~cm}$

Dissertação (mestrado)-Pontifícia

Universidade Católica do Rio de Janeiro, Departamento de Administração, 2010.

Inclui bibliografia

1. Administração - Teses. 2. Estrutura organizacional. 3. Bens e serviços B2B. 4. Processo de mudança. I. Tomei, Amélia. II. Pontifícia Universidade Católica do Rio de Janeiro. Departamento de Administração. III. Título. 
Este trabalho é dedicado ao meu filho Arthur que chegou no meio deste curso e me desafiou a concluí-lo. Com seus olhares e sorrisos intransponíveis, carregados de uma sedutora "alegria carente”, fez com que a finalização deste trabalho se tornasse uma verdadeira conquista, muito mais valiosa do que seria sem ele. 


\section{Agradecimentos}

À minha esposa Ingrid pelo companheirismo, incentivo, paciência e coragem de me dar um filho, mesmo com todas as nossas incertezas na vida, e ainda por cima cuidar dele todo o tempo durante este trabalho, além de ter me apoiado nas horas que mais precisei emocionalmente.

À minha mãe Marlene pela educação, carinho, dedicação, garra e exemplo de perseverança, que me ensinaram a ter força para conquistar todos os meus sonhos, viver minhas paixões intensamente sem esperar nada em troca e, ao mesmo tempo, ter a simplicidade de enxergar e dar valor às pequenas coisas e momentos da vida.

Ao meu pai, Jucy da Silveira, cujo exemplo, educação e orientação moral marcaram profundamente minha vida, tornando os valores atuais da humanidade quase inaceitáveis por mim, mas que ao mesmo tempo me permitem manter a capacidade de, todos os dias, colocar a cabeça no meu travesseiro e dormir profundamente.

À minha orientadora, Patrícia Amélia Tomei, pela alegria e respeito, pouco vistos no mundo acadêmico, não só na orientação da elaboração deste trabalho, mas também na profunda capacidade de motivação para a execução do mesmo. 


\section{Resumo}

Silveira Jr., Jucy da; Tomei, Patricia Amélia. A Tipologia de Mintzberg Aplicada nos Modelos de Gestão de Serviços B2B no Mercado de Telecomunicações Brasileiro. Rio de Janeiro, 2010. 96p. Dissertação de Mestrado - Departamento de Administração - Pontifícia Universidade Católica do Rio de Janeiro.

Este trabalho partiu da premissa de que as operadoras do mercado de telecomunicações brasileiro vêm forçando uma mudança de foco de bens para serviços, exigindo uma adaptação das estruturas organizacionais da indústria para responder a esta necessidade. Com base na tipologia de Mintzberg foi feita uma pesquisa exploratória e qualitativa, com levantamento de dados primários através entrevistas semi-estruturadas em uma amostra aleatória de gerência média de cinco multinacionais do setor para analisar como colaboradores de gerência média ou cúpula local interpretam estas mudanças. Os resultados encontrados nos acenaram que as mudanças estruturais propostas eram relacionadas a processos e não especificamente ao problema. Elas se relacionam com: (a) a importância do poder da tomada de decisão centrado na gerência média; (b) a especialização como forma de estrutura das divisões de trabalho; (c) o fortalecimento das correlações horizontais através de mecanismos de ligação; (d) o incentivo das relações interpessoais; (e) o fortalecimento do sistema de recompensas, com limitada punição e (f) a intensificação da comunicação horizontal. Assim, constatou-se que a necessidade de mudança de demanda, na verdade, é uma necessidade de mudança de foco, com novo posicionamento tanto nas ofertas como na gerência de projetos para quase toda a indústria. Por fim, identificou-se também que todas as empresas estudadas apresentaram sinais de mudanças estratégicas, tais como metas e modelos de negócios para serviços, confirmando a premissa do trabalho.

\section{Palavras-chave}

Estrutura organizacional; bens e serviços B2B; processo de mudança. 


\section{Abstract}

Silveira Jr., Jucy da; Tomei, Patricia Amélia (Advisor). Mintzberg's Typology Applied to Services B2B Management Models in Brazilian Telecommunications Market. Rio de Janeiro, 2010. 96p. MSc. Dissertation - Departamento de Administração, Pontifícia Universidade Católica do Rio de Janeiro.

This work started from the premise that operators of the Brazilian telecommunications market have forced a shift in focus from goods to services, requiring an adjustment of the organizational structures of industry to meet this need. Based on the typology of Mintzberg there was an exploratory and qualitative research with primary data gathered through semi-structured in a random sample of middle managers in five multinational of the sector to examine how middle management or employees of local umbrella interpret these changes. The results found alerted us that the proposed structural changes were related to processes and not specifically to the problem. They related to: (a) the importance of the power of decision-making centered in middle management; (b) specialization as a way to structure the division of labor; (c) the strengthening of horizontal correlations through bonding mechanisms; (d) the encouragement of interpersonal relations; (e) strengthening the system of rewards, with limited punishment; (f) the intensification of horizontal communication. Thus, it was found that the need for a change in demand, is actually a need to change the focus, with new positioning in both supply and project management for almost any industry. Finally, it was found also that all the companies studied showed signs of strategic changes, such as goals and business models for services, confirming the premise of the study.

\section{Keywords}

Organizational structure; goods and services B2B; management change 


\section{Sumário}

1. Introdução 12

1.1. Problema 13

1.2. Objetivo Final 15

1.3. Objetivos Intermediários e Questões para Análise 15

1.4. Relevância do Estudo 16

$\begin{array}{ll}\text { 1.5. Delimitação do Estudo } & 17\end{array}$

2. Referencial Teórico 18

2.1. Serviços B2B: O Crescimento de Serviços no Setor de

2.2. Transformação da Lógica de Marketing: de Bens para Serviços 19

2.3. Estrutura: Sua Importância no Alinhamento Estratégico 22

2.4. Conceitos de Estrutura 25

2.5. Configuração Estrutural de Mintzberg 31

3. Metodologia 36

3.1. Tipo de Pesquisa $\quad 36$

3.2. Estratégia de Investigação 36

3.3. Papel do Pesquisador 37

3.4. Procedimento de Coleta de Dados 37

3.5. Seleção dos Sujeitos 39

3.6. Procedimento de Registro de Dados 40

3.7. Limitações do Método 41

4. Mercado - Setor de Telecomunicações 43

4.1. Histórico das Telecomunicações no Brasil 43

4.1.1. Privatização do Setor de telecomunicações 44

4.1.2. Evolução do Mercado Brasileiro após Privatização 44

4.1.3. Evolução do Mercado Brasileiro dentro do Cenário
Global.

4.2. Principais Empresas da Indústri de Telecomunicações
Mundial

4.3. Tendências para a Evolução do Setor 50

5. Análise e Interpretação dos Dados 53

5.1. Descrição da Coleta de Dados e Classificação dos

5.1.1. Entrevistados: Envolvimento com o Problema 54

5.2. Existência do Problema Segundo Depoimentos 56

5.3. Existência do Problema Segundo Configuração Estrutural 61

5.4. Análise Entrevistas Seundo Modelo Conceitual de
Tipologia da Configuração Estrutural de Mintzberg

5.4.1. Tomada de Decisão 69

5.4.2. Orientação das Atividades do dia a dia dos Profissionais $\quad 71$

5.4.3. Divisões de Trabalho e Responsabilidades 73

5.4.4. Divisão de Unidades de Negócio 76

5.4.5. Correlação Horizontal entre as Áreas 76 
5.4.6. Relações Interpessoais

5.4.7. Sistemas de Recompensas e Punições

79

5.4.8. Sistema de Comunicações e Punições

6. Conclusão

83

7. Referências Bibliográficas

8. Anexos

89 


\section{Lista de figura}

Figura 1 - A evolução para uma nova lógica, apresentada por Vago \& Lusch (2004)

Figura 2 - As cinco partes básicas das organizações

Figura 3 - Os 5 tipos de descentralização 


\section{Lista de tabelas}

Tabela 1 - A evolução das teorias e práticas de marketing, apresentada por Vargo \& Lusch (2004)

Tabela 2 - Comparação das lógicas de marketing para bens e serviços, apresentada por Vargo \& Lusch (2004)

Tabela 3 - A Tipologia Blau e Scott apresentada por Frajtag (2002)

Tabela 4 - A Tipologia de Etzioni apresentada por Frajtag (2002)

Tabela 5 - Evolução anual do número de acessos fixos instalados no Brasil

Tabela 6 - Evolução anual de assinantes

Tabela 7 - Evolução anual de penetrações de serviços nos domicílios

Tabela 8 - Evolução anual de celulares nos países do BRIC

Tabela 9 - Evolução anual de telefones fixos nos países do BRIC

Tabela 10 - Evolução de banda larga nos países do BRIC

Tabela 11 - Evolução da receita das principais empresas globais do setor

Tabela 12 - evolução da receita relativa de serviços da Acatel-

Lucent nos últimos 4 anos

Tabela 13 - Evolução da receita relativa de serviços da

Ericsson nos últimos 3 anos

Tabela 14 - Evolução da receita relativa de serviços da Cisco nos últimos 4 anos

Tabela 15 - Resumos das respostas às perguntas de 1 a 4

Tabela 16 - Resumo das respostas do parâmetro da tomada de decisão

Tabela 17 - Resumo das respostas do parâmetro coordenação de atividades do dia-a-dia

Tabela 18 - Resumo das respostas do parâmetro de divisão de trabalhos e responsabilidades

Tabela 19 - Resumo das respostas do parâmetro de correlação horizontal entre as áreas

Tabela 20 - Resumo das respostas do parâmetro de relações interpessoais

Tabela 21 - Resumo das respostas do parâmetro de premiações e punições

Tabela 22 - Resumo das respostas do parâmetro de sistema de comunicações 